\title{
Risk Progression in Adolescent Idiopathic Scoliosis: Literature Review and Scale Proposal
}

\section{de Araujo Ono $\mathrm{AH}^{* 1}$, Marcon $\mathrm{RM}^{1}$, Guiroy $\mathrm{A}^{2}$, Cristante $\mathrm{AF}^{1}$ and de Barros Filho TEP ${ }^{1}$}

${ }^{1}$ Faculty of Medicine, University of São Paulo, Hospital das Clínicas, Institute of Orthopedics and Traumatology, São Paulo, Brazil

${ }^{2}$ Spanish Hospital, Mendoza, Argentina

*Corresponding author: de Araujo Ono AH, Faculty of Medicine, University of São Paulo, Hospital das Clínicas, Institute of Orthopedics and Traumatology, São Paulo, Brazil, Tel: +5511982812961, E-mail: allanmedcoluna@gmail.com

Citation: de Araujo Ono AH, Marcon RM, Guiroy A, Cristante AF, de Barros Filho TEP (2021) Risk Progression in Adolescent Idiopathic Scoliosis: Literature Review and Scale Proposal. J Orthop Physiother 4(1): 104. doi: 10.15744/2639-930X.4.104

Received Date: May 09, 2021 Accepted Date: June 02, 2021 Published Date: June 04, 2021

\begin{abstract}
Objective: To identify the main risk factors for the progression of adolescent idiopathic scoliosis and to create a tool or classification that helps to identify patients with greater potential for the development of serious scoliosis.

Summary of background data: Adolescent idiopathic scoliosis (AIS) is a three-dimensional deformity of the vertebral column. The risk of progression of the curves increases without intervention from diagnosis to skeletal maturity and the long queues for surgery is a problem in most public health services. There is still no practical tool to estimate the progression and prognosis of the disease.

Methods: A systematic search was performed in the bibliographic databases PubMed, Google Scholar, and Bireme databases, using the descriptors Scoliosis AND Adolescent AND risk AND progress. Two authors independently assessed methodological quality. Data were extracted and presented according to a best evidence synthesis.

Results: After verification of the 46 articles, nine risk factors were identified: Curve Magnitude at Presentation, progression at 1 year, Risser's signal, waiting time for surgery, type of curve, rotation of the apical vertebra, thoracic kyphosis, selfimage, and spinopelvic balance. Curve Magnitude at Presentation is the most important predictive factor of progression. The Scale SSS-IOT (Scoliosis Severity Score-I) was developed, assigned to each of the above criteria, with a higher score for worse prognosis factors and the lowest score for lower risk of progression or better prognosis factors. The final result is the sum of the scores in a single query.
\end{abstract}

Conclusions: The proposed scale aims to support regional characteristics needs and can be improved over time. Studies with clinical correlation are necessary for its implantation. The adoption of criteria for the organization of the surgical row aims at better attending patients who would have greater benefits, fewer risks for surgical treatment, with better costeffectiveness.

Keywords: Scoliosis; Adolescent Idiopathic Scoliosis; Surgery; Classification; Scale; Risk; Progression; Prognosis; Health Services; Spine; Waiting Lists 
Mini Abstract/Précis: Adolescent idiopathic scoliosis is a vertebral column deformity, which increases without intervention. A systematic search was performed to identify risk factors for the AIS progression and create a tool to identify potential developers of serious scoliosis. We identified 9 risk factors and developed a simple scale called Scoliosis Severity Score-I.

\section{Introduction}

Adolescent idiopathic scoliosis (AIS) is a three-dimensional deformity of the vertebral column, marked by the rotation of the vertebral bodies in the axial plane and deviation in the coronal plane of 10 degrees. Its manifestation occurs predominantly between 10 and 18 years, usually does not cause pain or neurological alterations, however, it generates a large impact in physical and psychosocial aspects [1]. It is the most common deformity of the spine, affecting from $0.5 \%$ to $3 \%$ of the school-age population. The female gender is predominant, being 2: 1 in general and 8: 1 in the most severe cases, requiring surgical correction [2-4].

In most countries with public health services, due to the increasing demand and difficult access to resources essential for surgery, such as instrumental, neurophysiological follow-up, need for ICU beds, high cost, low number of qualified surgeons, there are long queues [5]. Júnior et al. (2011) studied the waiting list for surgical treatment of AIS in a public hospital in São Paulo and found 51 patients waiting for 2 to 180 months [6]. In Hospital das Clínicas of São Paulo, the biggest public hospital in Latin America, in 2019 scoliosis surgery waiting list reached 281 cases with minimum waiting time of 4 years.

The risk of progression of the curves increases without intervention from diagnosis to skeletal maturity [7]. Girls of pubertal age $(10,11,12$ years) who present curves above 30 degrees at diagnosis are prone to progress in $90 \%$ to $100 \%$ of cases [8].

The natural evolution of idiopathic scoliosis was extensively studied and several risk factors were analyzed to determine the risk of progression in different populations [9-11]. Despite the efforts, there is still no practical tool that uses the risk factors to estimate the progression and prognosis of the disease. Lostein and Carlson (1984) proposed an arithmetic formula to predict the scolioses progress, using the Risser's sign, the Cobb angle and chronological age, but the formula was not reproducible in other populations [12]. In the current public health scenario, patients wait months to years for surgery in a list formed by order of entry. It is estimated that many of the patients had a significant progression of the diagnosis, with more severe and rigid curves at the time of surgery, resulting in longer surgeries, longer hospitalization and greater need for additional surgery. In this logic, the patient who presents the best benefit of surgical treatment is one that has a higher potential for scoliosis progression.

The aim of this review is to identify the main risk factors for the progression and prognosis of AIS according to the current literature and create a score that helps to identify patients with greater potential for the increases of who are at risk for rapidly progressing scoliosis waiting list of patients' candidates for surgery. We consider that surgery may benefit patients that are in risk of progression more than patients that have slow progression or have already progressed. This could organize waiting lists like occurs in liver tranplatation tha uses MELD score system [13].

\section{Materials and Methods}

A review protocol was delveloped using Prefered Reporting Items for Systematic Reviews and Meta-Analyses (PRISMA) Checklist. A systematic search was performed in the bibliographic databases PubMed, Google Scholar, and Bireme databases, using the following descriptors (MeSH terms): Scoliosis AND Adolescent AND risk AND progression. Search terms expressing "Adolecent Scoliosis" were combined with search terms as "progression" or "risk progression" conducted by an experient author, and backwards citation of obtained articles. Search were restricted to studies with humans, without date limit, of any desing, abstract must be in English. The survey was conducted in September 2017. Two reviewers (AHO and RMM) independently screened titles, abstracts and full text articles indentified by the literature search. All Full Text articles were selected for further selction of eligibility. 


\section{Eligibility criteria}

It was included review studies, clinical trials, prospective case series, retrospective observational studies, and cross-sectional studies with full text available. Case series type study, preliminary protocols, editorials and conference presentations were excluded. We excluded articles without abstract available on the digital platform, articles related to other types of scoliosis like degenerative, neuromuscular or congenital, genetic studies, laboratorial studies, in vitro studies, post-operative studies and studies performed after skeletal maturity.

\section{Studies selection}

Previous articles were selected by titles, excluding those not included in the eligibility criteria, duplicate or irrelevant articles for the subject, considering risk factors for progression to adolescent idiopathic scoliosis, based on anthropometric data, questionnaires, and simple radiographs, without the need for further examination. After sorting by title, Full-Text of the remaining articles were reviewed by $\mathrm{AHO}$ and RMM.

\section{Ethical Approval}

This study obtained approval from the Ethics and Research Committee Review Board. And online protocol were registred in Plataforma Brasil.

\section{Results}

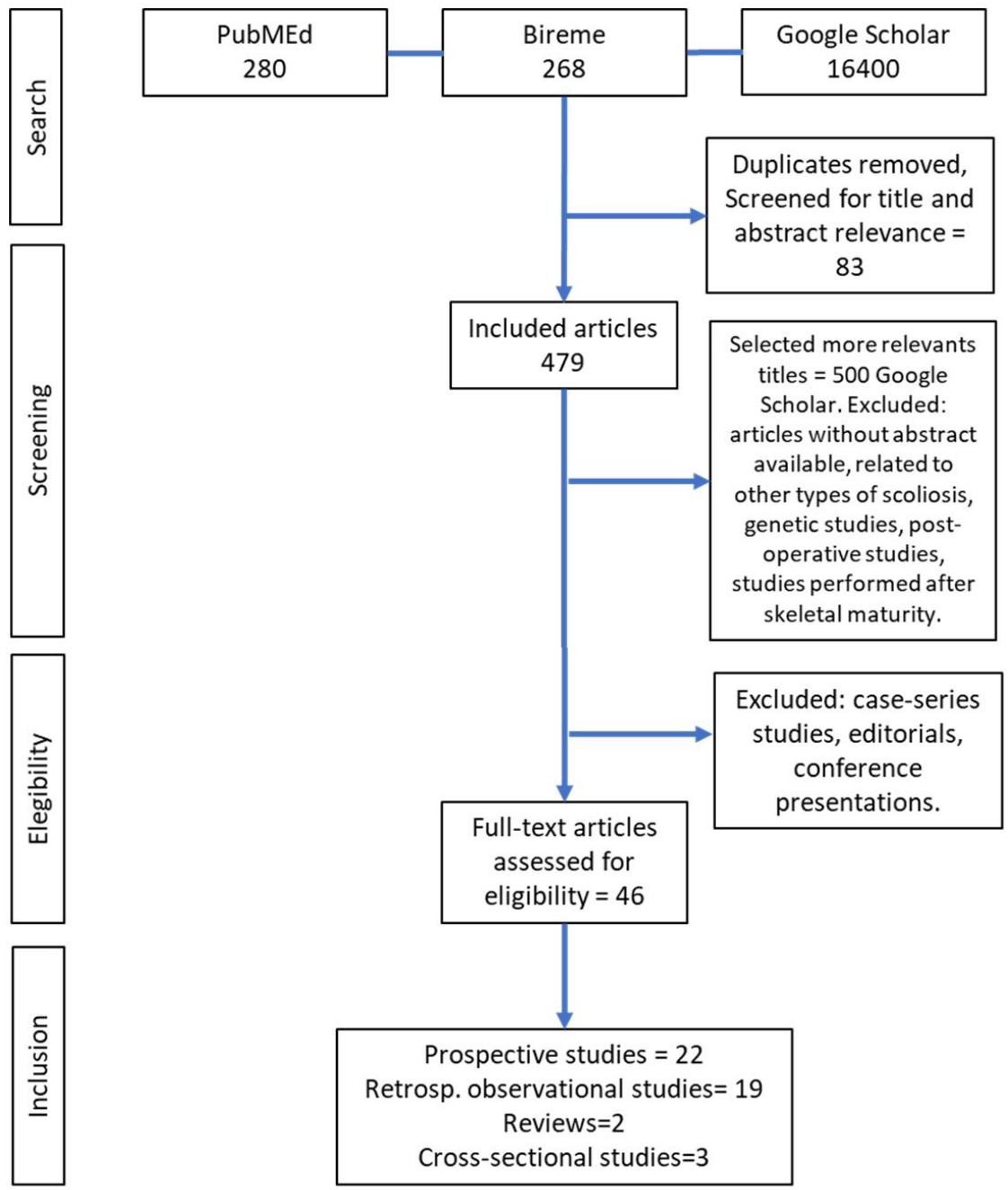

Figure 1: Study selection process 
The search resulted in 280 citations in PubMed, 268 in Bireme and 16,400 in Google Scholar. We consider the titles of the 500 most relevant Google Scholar. After the exclusion of duplicate articles, 83 were selected for the relevance of titles and abstracts. Of these, 46 were selected because they met the inclusion criteria and were read in full. Three articles, one Italian, German and Chinese, required the translation of the full text, carried out in the Google Translate tool. The article selection process is summarized in Figure 1.

The selection criteria were 22 prospective case series, 19 retrospective observational studies, 2 reviews, and 3 cross-sectional studies.

\section{Selection Biases}

The articles were selected by a single author, which can represent losses of works considered of little relevance by the same one. It was not possible to conduct a meta-analysis due to the diversity of methodologies and selection criteria of the selected studies. No specific evaluation was carried out on the quality of the articles included since it was intended to include as many articles as possible on the subject.

\section{Risk factors}

After verification of the 46 articles, nine risk factors that directly interfere with the evolutionary prognosis of the disease were identified: Curve Magnitude Scoliosis at Presentation, progression at 1 year, Risser's signal, waiting time for surgery, type of curve, rotation of the apical vertebra, thoracic kyphosis, self-image, and spinopelvic balance. Table 1 shows the main adolescent idiopathic scoliosis risk factors identified from the literature review.

\begin{tabular}{|c|c|c|}
\hline Author, year, journal & Main risk factors and determinants & Number of patients \\
\hline \multicolumn{3}{|l|}{ The magnitude of the curve in the presentation } \\
\hline Duval-Beaupère et al. 1985 Spine(28) & $\begin{array}{l}\text { A greater curve at the presentation - } \\
\text { high risk of progression }\end{array}$ & 159 \\
\hline Hung et. al. 2005 JBJS Am(29) & $\begin{array}{l}\text { Greater Cobb in the } \\
\text { beginning - determinant factor }\end{array}$ & 324 \\
\hline Lee et al. 2012 Spine $J(27)$ & $\begin{array}{l}\text { Cobb }>25,8^{\circ} \text { high risk; Cobb }<18,4^{\circ} \text { low risk } \\
\text { of progression }\end{array}$ & 2308 \\
\hline Noshchenko et al. 2015 World J Orthop.(30) & Higher Cobb in the beginning - Higher risk & 3719 \\
\hline Soucacos et al. 1998 Eur Spine J(2) & $\begin{array}{l}\text { Cobb } 10^{\circ}-20^{\circ}=11-20 \% \text { risk of progression; } \\
\text { Cobb }>30^{\circ}=48 \% \text { risk of progression }\end{array}$ & 839 \\
\hline Sun et al. 2010 Orthop $\operatorname{Surg}(23)$ & $\begin{array}{l}\text { Cobb } 20^{\circ}-30^{\circ}=11 \% \text { surgical indication; } \\
\text { Cobb }>30^{\circ}=89 \% \text { surgical indication }\end{array}$ & 142 \\
\hline Sun et al. 2013. J Pediatr Orthop(25) & $\begin{array}{l}\text { Cobb } 31^{\circ}-40^{\circ} \text { high risk of progression } \\
(\text { OR } 6,73)\end{array}$ & 68 \\
\hline Tan et al. 2009. Spine(22) & Cobb $>25^{\circ}=$ higher risk of progression & 186 \\
\hline Xu et al. 2011 Eur Spine J(24) & $\begin{array}{l}\text { Cobb }>30^{\circ}=32 \% \text { risk of progression; } \\
\text { Cobb }<30^{\circ}=27 \% \text { risk progression }\end{array}$ & 312 \\
\hline
\end{tabular}




\begin{tabular}{|c|c|c|}
\hline Author, year, journal & Main risk factors and determinants & Number of patients \\
\hline Zhang et al. 2015 Eur. Spine J.(26) & Cobb $>35^{\circ}=$ high risk of progression & 89 \\
\hline \multicolumn{3}{|l|}{ 1-year progression } \\
\hline Charles et al. 2006 Spine(17) & $\begin{array}{l}70 \% \text { of patients with progression } 6^{\circ}-10^{\circ} \\
\text { year; } 100 \% \text { of patients with progression }\end{array}$ & 205 \\
\hline Coillard et al. 2014 Eur J Phys Rehabil Med(31) & $\begin{array}{l}\text { Cobb }>6^{\circ} \text { of progression }= \\
\text { faillure of traditional treatment }\end{array}$ & 68 \\
\hline Escalada et al. 2009 Scoliosis(34) & Cobb $>5 \%$ year & 132 \\
\hline Mao et al. 2016 Eur Spine J.(32) & Cobb $>6 \%$ year $=$ progressive scoliosis & 95 \\
\hline Shi et al. 2015 Scoliosis(33) & $\begin{array}{l}\text { Cobb }>5^{\circ} \text { of progression }= \\
\text { faillure of traditional treatment }\end{array}$ & 30 \\
\hline \multicolumn{3}{|l|}{ Skeletal Maturity (Risser Sign) } \\
\hline Ahn et al. 2011 Can Med Assoc J(9) & $\begin{array}{l}\text { Lower Risser }=\text { higher risk for } \\
\text { post-surgical adverse events }\end{array}$ & 216 \\
\hline Modi et al. 2009 J Spine Disord Tech(39) & $\begin{array}{l}\text { No correlation between } \\
\text { Risser and progression }\end{array}$ & 113 \\
\hline Nault et al. 2010 JBJS(38) & $\begin{array}{l}\text { Risser } 0 \text { and } 1 \text { non-accurate but } \\
\text { predict evolution }\end{array}$ & 100 \\
\hline Noshchenko et al. 2015 World J Orthop.(30) & Risser 0 and 1 (OR 1,5 - 5,1) & 1891 \\
\hline Sun et al. 2010 Orthop Surg(23) & $\begin{array}{l}\text { Risser }<2=78 \% \text { risk of progression; }= \\
\text { Risser }>2=28 \% \text { risk of progression }\end{array}$ & 142 \\
\hline Sun et al. 2013. J Pediatr Orthop (25) & $\begin{array}{l}\text { Risser } 0-1 \text { = higher risk factor } \\
\text { for progression }\end{array}$ & 68 \\
\hline $\begin{array}{l}\text { Winiarski et al. } 2005 \text { J Orthop Traumatol } \\
\text { Rabil(40) }\end{array}$ & Risser $=$ only accurate progression factor & 159 \\
\hline Xu et al. 2011 Eur Spine J(24) & $\begin{array}{l}\text { Risser } 0-1 \text { = higher risk factor } \\
\text { for progression }\end{array}$ & 312 \\
\hline Zhang et al. 2015 Eur Spine J (26) & $\begin{array}{l}\text { Risser }<2=\text { high risk for progression } \\
(\text { OR 6,13) }\end{array}$ & 89 \\
\hline \multicolumn{3}{|l|}{ Waiting time for surgery } \\
\hline Ahn et al. 2011 Can Med Assoc J(9) & $\begin{array}{l}\text { Long wait time }>6 \text { months }=\text { higher risk for } \\
\text { further surgery }\end{array}$ & 216 \\
\hline
\end{tabular}


Journal of Orthopaedics and Physiotherapy

\begin{tabular}{|c|c|c|}
\hline Author, year, journal & Main risk factors and determinants & Number of patients \\
\hline Calman et al. 2013 ANZ J Surg (41) & $\begin{array}{l}\text { Average waiting time }=320 \text { days (mean }= \\
216 \text { days); More than } 6 \text { months waiting the } \\
\text { surgery = poor quality of life }\end{array}$ & 70 \\
\hline Dabke et al. 2005(42) & $\begin{array}{l}\text { More than } 11 \text { months waiting }=58 \% \text { needed } \\
\text { additional surgery; Cobb increased from } \\
40^{\circ} \text { to } 84^{\circ}\end{array}$ & 101 \\
\hline \multicolumn{3}{|l|}{ Type of Curve } \\
\hline Lara et al. 2017 Spine Deformity J (43) & $\begin{array}{l}\text { Double thoracic, higher surgical } \\
\text { rate }=57,9 \%\end{array}$ & 223 \\
\hline Soucacos et al. 1998 EurSpineJ (2) & $\begin{array}{l}\text { Risk of progression }=\text { double curve }=21 \% \text {; } \\
\text { thoracic curve }=16 \% \text {; lumbar curve }=14 \% \text {; } \\
\text { Thoracic-lumbar curve }=10 \%\end{array}$ & 839 \\
\hline Sun et al. 2013. J Pediatr Orthop (25) & $\begin{array}{l}\text { Thoracic curve = more progressive } \\
(\mathrm{OR} 11,2)\end{array}$ & 68 \\
\hline Weinstein et al. 1981 JBJS (20) & $\begin{array}{l}\text { Progression in } 40 \text { years }=\text { Thoracic curves }= \\
29,5^{\circ} ; \text { Double curves }=20^{\circ} \text { each curve }\end{array}$ & 133 \\
\hline Xu et al. 2011 Eur Spine J (24) & $\begin{array}{l}\text { Thoracic curve }=32 \% \text { risk of progression; } \\
\text { Double curve }=24 \% \text { risk of progression }\end{array}$ & 312 \\
\hline Ylikoski et al. 2005 J Pediatr Orthop(44) & Right thoracic curve $=$ main progression & 535 \\
\hline \multicolumn{3}{|l|}{ Rotation of the apical vertebra } \\
\hline Nault et al. 2013 J Pediat Orthop(45) & $\begin{array}{l}\text { Progressive group }=7,7^{\circ} \text { increased } \\
\text { apical vertebral rotation }\end{array}$ & 37 \\
\hline Nault et al. 2014 Spine(46) & $\begin{array}{l}\text { Progressive group }=2,4^{\circ} \text { increased } \\
\text { vertebral rotation }\end{array}$ & 133 \\
\hline Rigo et al. 2006 Stud Health Technol Inform(49) & $\begin{array}{l}\text { Progressive cases = higher apical } \\
\text { vertebral rotation }\end{array}$ & 253 \\
\hline \multirow[t]{3}{*}{ Villemure et al. 2001 Spine (47) } & Progression related to rotation & 28 \\
\hline & & Continue \\
\hline & & Continued \\
\hline Weinstein e Ponseti 1983 JBJS(18) & Vertebra rotation $=$ prognose fator & 102 \\
\hline Yamauchi et al. 1988 Spine(48) & $\begin{array}{l}\text { Vertebra rotation }=\text { related to } \\
\text { scoliosis progression }\end{array}$ & 122 \\
\hline
\end{tabular}




\begin{tabular}{|c|c|c|}
\hline Zhang et al. 2015 Eur Spine J.(26) & Vertebra rotation $>$ grade $\mathrm{III}=(\mathrm{OR} 16,13)$ & 89 \\
\hline \multicolumn{3}{|l|}{ Thoracic kyphosis } \\
\hline Cheung et al. 2006 Spine(56) & Low kyphosis in progressive cases & 105 \\
\hline Guo et al. 2012 Eur Spine J(58) & Kyphosis not related to progression & 60 \\
\hline Jiang et al. 2011 Zhonghua Wai Ke Za Zhi (60) & $\begin{array}{l}\text { Severe progression }=\text { Thoracic kyphosis } \\
8^{\circ} \pm 5^{\circ} \text {; Mild progression }=\text { Thoracic } \\
\text { kyphosis } 13^{\circ} \pm 6^{\circ}\end{array}$ & 83 \\
\hline Mannherz et al. 1988 Spine(57) & Progressive cases $=$ Kyphosis $<20^{\circ}$ & 43 \\
\hline Nault et al. 2014 Spine(46) & Progressive cases $=$ Kyphosis $<4,4^{\circ}$ & 133 \\
\hline Ran et al. 2014 J Orthop Surg Res(59) & High progressive group $=$ Kyphosis $=4^{\circ}-9^{\circ}$ & 97 \\
\hline Rigo et al. 2006 Stud Health Technol Inform(49) & $\begin{array}{l}\text { Progressive cases = decrease in } \\
\text { thoracic kyphosis and lumbar lordosis }\end{array}$ & 253 \\
\hline Villemure et al. 2001 Spine(47) & $\begin{array}{l}\text { Lower kyphosis grade }=\text { poor } \\
\text { angle deformity }\end{array}$ & 28 \\
\hline Ylikoski et a.1 2005 J Pediatr Orthop(44) & Lower kyphosis = progression factor & 535 \\
\hline \multicolumn{3}{|l|}{ Self-image } \\
\hline Brox et al. 2014 Eur J Phys Rehabil(53) & $\begin{array}{l}\text { Comorbidities related to disease } \\
\text { progression compromise self-image }\end{array}$ & 390 \\
\hline Carrasco et al. 2014 Rev Esc Enferm USP (51) & $\begin{array}{l}\text { Self-image worse proportional to } \\
\text { Cobb, improvement with surgery }\end{array}$ & - \\
\hline Freidel et al. 2002 Spine(50) & $\begin{array}{l}\text { Suicidal ideation (OR 1.4); Feeling of } \\
\text { poor body development (OR 1.82) }\end{array}$ & 685 \\
\hline Roberts et al. 2011 Spine(54) & $\begin{array}{l}\text { The sensation of self-image improves } \\
\text { significantly with correction surgery }\end{array}$ & 744 \\
\hline Sapountzi-Krepia et al. 2006 Scoliosis (52) & Feelings of shame, denial, stress and anger & 12 \\
\hline \multicolumn{3}{|l|}{ Spinopelvic (sagittal) balance } \\
\hline Jiang et al. 2011 Zhonghua Wai Ke Za Zhi (60) & $\begin{array}{l}\text { No correlation with sagittal balance } \\
\text { and spinopelvic parameters }\end{array}$ & 83 \\
\hline La Maida et al. 2013 Eur Spine J(62) & $\begin{array}{l}\text { Scoliosis surgery changes the sagittal } \\
\text { and spinopelvic balance }\end{array}$ & 76 \\
\hline
\end{tabular}




\begin{tabular}{|l|l|l|}
\hline Author, year, journal & Main risk factors and determinants & Number of patients \\
\hline Ries et al 2015 Spine (63) & $\begin{array}{l}\text { Selective fusions do not alter the } \\
\text { patients' spinopelvic balance }\end{array}$ & 50 \\
\hline Roussouly et al. 2013 Eur Spine J(61) & $\begin{array}{l}\text { Different Spinopelvic Parameters of } \\
\text { Adult Scoliosis }\end{array}$ & 184 \\
\hline Yong et al. 2012 Spine (64) & $\begin{array}{l}\text { No difference in pelvic hawthorn parameters } \\
\text { in the group without AIS }\end{array}$ & 128 \\
\hline
\end{tabular}

Table 1: Main adolescent idiopathic scoliosis risk factors identified from the literature review

\section{Curve Magnitude Scoliosis at Presentation}

The curve magnitude of scoliosis at presentation is the most important predictive factor in determining the progression of a scoliotic curve above 30 degrees. An initial Cobb angle of 25 had a positive predictive value of $68.4 \%$ and a negative predictive value of 91.9\% for scoliosis progression for curves above 30 degrees, the initial minimum value to determine the progression of the curve in the treatment of long-term scoliosis [14]. A lower percentage of correction and a greater number of complications is expected for larger curves at the presentation in skeletally immature patients [9]. The maximum Cobb final angle of a curve is directly correlated with the initial angle [3,8,9,14-16]. Duval-Beaupère and Lamireau (1985) followed 139 patients with AIS, all with lower major curves of 30 degrees, $83 \%$ of these patients had a progression lower than 6 degrees, not requiring surgery [28].

\section{Progression at 1 year}

The progression of more than 5 degrees every 6 months is a strong predictor of the progression of the curve. Patients who are being treated with vest and show a progression between 6 and 10 degrees, representing a warning sign for possible failure. The progression of more than 10 degrees means failure of this treatment and general indication of surgery $[17,18]$.

Curves that progressed from 6 to 10 degrees per year needed to be operated in $70.9 \%$ of cases, while those who progressed more than 10 degrees in 1 year required surgery in $100 \%$ of cases [8,19-22]. The progression of scoliosis in relation to time was called the angular velocity of the curve by Escalada et al. (2009), this is the current Cobb subtracted from the Cobb measured in the previous query, divided by the time interval. According to the author, it is an evolution variable that does not follow the same pattern of growth velocity in height of the patient [34].

\section{Skeletal Maturity (Risser)}

The Risser's signal is easily identifiable on panoramic radiographs of patients with scoliosis in the frontal incidence. This sign is a well-known marker of bone growth. Patients in stages 0,1 and 2 had a higher growth potential and were slower in phases 3, 4 and 5. A meta-analysis considering 4 studies and 1,891 patients demonstrated a statistically significant association of Risser 0 and 1 with the progression of the curves of scoliosis, with odds ratio ranging from 1.5 to $5.1(p<0,001)$ [23].

Patients who were on the waiting list for surgery for more than six months had a worse correction, more complications, and those who waited less than six months required fewer reoperations, presented greater correction capacity with fewer complications [24]. The longer waiting time was associated with the lower score in the SRS quality of life questionnaire (0.13 points for 6 months, $p=0,01)$. Within the SRS-30 questionnaire, the pain, treatment satisfaction and self-image domains showed statistically significant worsening with increased waiting time. The longer the waiting time, the worse was the pain $(p=0.02)$, satisfaction with treatment $(p<0.05)$ and self-image domains $(p<0.01)$ [25]. Dabke et al. (2005) followed 101 patients who waited for about 11 months for surgery, and the initial Cob ranged from $40^{\circ}$ at the first consultation to $84^{\circ}$ at the time of surgery. The author concluded that long periods of waiting negatively affect the prognosis and results of surgery [42]. 


\section{Type of curve}

Curve patterns are also directly correlated with progression criteria. Soucacos et al. (1998) followed a cohort of 839 children with AIS for an average of 3.2 years. They found that the thoracic curves or double curves in girls tend to have greater progression than the left or lumbar thoracic curves [2]. Weinstein and Ponseti (1983) followed a cohort of 133 patients for 40 years and found that the thoracic curves between 50 and 75 degrees progressed on average 29.5 degrees, while the other types of curve presented a lower evolution. Secondly, the combined double curves between 50 and 75 degrees suffered great progression, with a mean of 18.3 and 23.1 for the lumbar. The other curve patterns were less progressive [18].

The thoracic curves and the thoracic and lumbar pairs showed a higher rate of progression, even after skeletal maturity. Lee et al. (2012) treated 95 patients, conservatively and the lowest success rates for the curve type were found in patients with a double curve and an isolated thoracic curve [27]. Other retrospective studies have found that the right thoracic curves are more likely to progress. Sun et al. (2013) followed 68 girls with curves greater than 45 degrees and also detected the predominance of the thoracic curves, especially when associated with osteopenia [25].

\section{Apical vertebra}

In 1981, Perdriolle and Vidal looked for aggressive curves with an important torsional component and observed that patients with the apical vertebra of the main curve with rotations greater than $33 \%$ also presented more aggressive scoliosis (ref). Weinstein and Ponseti (1983) followed 102 patients with idiopathic scoliosis after skeletal maturity for an average of 40.5 years, finding several predictive factors of progression. In patients with the apical vertebra of rotation higher than $30 \%$ and lateral deviation relative to the vertebra L5, the progression of the curve was higher occurring even in the lower lumbar curves 30 degrees [9]. Years later, Lenke et al. (2001) classified the deviation of the apical vertebra relative to a line crossing the center of the sacrum in the coronal plane into three types, being this the type C Curves greater than 30 degrees with rotation of the apical vertebra higher than $25 \%$ are twice as likely to progress [11,21].

\section{Self-image}

Self-image is an important factor in the quality of life of patients with idiopathic scoliosis, self-imprinting of an underdeveloped body can become one of the greatest relationship difficulties, low self-esteem and depression, as well as thoughts of suicidal ideation greater than control groups [26]. Untreated correctly scoliosis can cause significant psychosocial problems due to the adverse effects of the disease on body image [27]. Conservative treatments like the use of vest can exacerbate these problems. The psychological impact of using different types of data was validated through a quality of life questionnaires, showing that the patient with idiopathic scoliosis of adolescents is more likely to develop dissatisfaction with their body image [28,29]. Untreated scoliosis has potential effects such as pain, deformity, loss of lung capacity in more severe forms [10]. Few studies compare their physical and social restrictions with aspects related to loss of self-esteem [30]. However, when operated on, patients of both sexes are able to show improvement in the scores of mental health questionnaires [31]. Therefore, the effects of scoliosis on the patient's self-image and social life, despite being a subjective criterion, should be considered as a prognostic factor for the disease.

\section{Thoracic kyphosis}

Jiang et al. (2011) followed 83 children with idiopathic scoliosis by lateral radiography and concluded that patients with severe and moderate progression of the curve had, in their majority, low thoracic kyphosis, around $8^{\circ}+-5^{\circ}$, when compared to the group of scoliosis lightly progressive, with an average of $19^{\circ}+-7^{\circ}$ of thoracic kyphosis. Ran et al. (2014) analyzed 97 children and divided them into three groups. The patients with the highest risk of progression presented values of thoracic kyphosis between $9^{\circ}+-4^{\circ}$ and those with lower risk, values of $18^{\circ}+-6^{\circ}$. Thus, hypokyphotic patients are considered more prone to progression. Hypokyphosis influences the progression of the curves, being an important factor in the correction of scoliosis, which directly affects the patients' 
quality of life. Wiedenhöfer et al. (2011) prospectively compared two groups of patients operated on for correction of idiopathic scoliosis and inferred that groups with osteotomy-corrected hypokyphosis had a better overall sagittal balance and better scores on the questionnaire on health-related quality of life (HRQoL).

\section{Sagittal balance}

Roussouly et al. (2013) compared adolescent and adult scoliosis using pre and postoperative parameters and concluded that spinalpelvic balance in AIS does not have the same significance as in adult scoliosis, and its impact on patients' quality of life is irrelevant. La Maida et al. (2013) studied lateral radiographs of patients with AIS, and identified, for the most part, a slightly posterior displacement of the C7 plumb line (SVA). With the surgical treatment, the majority of the patients presented an even greater displacement, without clinical repercussions. Therefore, the sagittal balance, as well as the spinopelvic parameters, are not prognostic criteria of the disease in the adolescent and was not adopted in the scale.

\section{Design of the Scale}

\begin{tabular}{|c|c|c|}
\hline Clinical/Radiological characteristic & Range & Point \\
\hline \multirow{3}{*}{ Cobb in the beginning } & $<20^{\circ}$ & 0 \\
\hline & $20^{\circ}-30^{\circ}$ & 1 \\
\hline & $>30^{\circ}$ & 2 \\
\hline \multirow{3}{*}{1 year progression } & $<6^{\circ}$ & 0 \\
\hline & $6^{\circ}-10^{\circ}$ & 1 \\
\hline & $>10^{\circ}$ & 2 \\
\hline Risser score & I e II & 2 \\
\hline \multirow{4}{*}{$\begin{array}{l}\text { Waiting time (immature skeleton })^{*} \\
(\text { full mature }+1 \mathrm{pt} / \text { year })\end{array}$} & $<3$ months & 0 \\
\hline & 3-6 months & 1 \\
\hline & $>6$ months & 2 \\
\hline & 12 months & 3 \\
\hline \multirow{4}{*}{ Type of curve } & Thoracic principal & 2 \\
\hline & Combined & 2 \\
\hline & Thoracic-lumbar & 1 \\
\hline & Lumbar & 1 \\
\hline \multirow{2}{*}{ Apical vertebra } & Nash Moe $>3$ & 1 \\
\hline & Lenke C & 1 \\
\hline \multirow{3}{*}{ Self-image } & No aesthetic concern & 0 \\
\hline & Moderate aesthetic concern & 1 \\
\hline & High esthetic concern & 2 \\
\hline \multirow{3}{*}{ Thoracic Kyphosis } & Normal & 1 \\
\hline & Low Kyphosis & 2 \\
\hline & Hyper Kyphosis & 1 \\
\hline
\end{tabular}

Table 2: Scoring scale created for risk stratification of patients with adolescent idiopathic scoliosis (SSS - Scoliosis Severity Score) 
After the selection and verification of the scientific evidence, the Scoring Scale was developed for the risk stratification of patients with AIS. A simple score was assigned to each of the above criteria, with a higher score for worse prognosis factors and the lowest score for lower risk of progression or better prognosis factors. We atribuited 1, 2 or 3 points according to severity. Each variable receives a score and the final result is the sum of the scales assigned in a single query. The initial Cobb is based on the medical records or the first radiograph that led the patient to inclusion in the queue.

Imaging tests available in electronic medical records as well as information contained in the medical records can be used to search for required information. Table 2 shows the scale created, called Scoliosis Severity Score-I (SSS-IOT).

\section{Discussion}

Each of the prognostic criteria was supported by consistent scientific evidence and most of the results of the articles were convergent. Most of the studies analyzed are prospective case series, probably due to the great number of ethical impediments in performing randomized clinical trials with patients with AIS. The authorization of parents and guardians is mandatory and the concern for the welfare of the adolescent should be the priority. We found many retrospective studies with expressive numbers of patients, also with convergent results. The criteria "Curve Magnitude at Presentation” was unanimous, being perhaps the most important prognostic factor in this disease.

Due to the importance of sagittal balance in adult scoliosis, this parameter was the subject of several studies in AIS. The articles that analyzed it showed divergent results. The largest series of cases, 60 patients, showed that the relevance of sagittal balance in adolescents is not the same as in adult scoliosis. In these cases, this variable was not considered a prognostic factor.

Other risk factors related to the progression of scoliosis were identified. However, they were excluded from the scale proposed by the need for complementary tests, such as bone densitometry and genetic tests. In addition to being expensive and of low specificity, they were used in studies with low level of evidence or methodological failures [12,23]. Sanders et al. published in 2008 a score using the simplification Turnner-Whitehouse III RUS score that uses ephysial status of proximal, distal and medial phalangeal of 2 ulnar fingers (forth and fifth fingers), with good interobserver and intraobserver reliability, and good curve prediction considering girls with adolescent idiophatic scoliosis. Despite the good reliability and strong prediction value we didn't considered this score, due difficult of learning curve, and need of hand x-ray, what difficult assessment in clinical practice, raise costs and radiation exposure [32]. Our score objectives are to be as simple as possible and to consider other prognostic risks like self image, rotation, kyphosis and others factors that could impact not only curve progression but quality of life. Other factors related to skeletal maturity such as chronological age and menarche, already contemplated by Risser's sign and directly correlated, were also excluded, since they could make the scale redundant in order to obtain a scale that can be easily applied in single consultation, and in health services of various levels of complexity, with only an initial and current lateral radiograph, we use only simple criteria that are part of the AIS basic semiology and propaedeutics.

Waiting lists for surgeries are common in all countries with a public health system. They generate public dissatisfaction and political concern, in part because they cause prolonged suffering, worsening of the pathological condition, pain and, in some cases, the death of their patients [33]. According to the 2017 estimate of the SISREG (Brazilian Federal Government Regulation System), more than 800 thousand people are waiting for some type of elective surgery by the Unified Health System, most of them orthopedic [34]. Doctors and patients have the perception that waiting lines are not fair, and this exacerbates dissatisfaction [35].

The scale created has limitations and cannot be generalized. It was not possible to define mathematically which of the nine criteria had greater influence or greater importance in the prognosis of AIS. This would require complex calculations, which would make it difficult to scale. In addition, the points were given empirically, considering that the risk factors do not present the same value between them. Due to the diversity of methodologies adopted, a qualitative analysis of the studies was not performed, which invalidated the meta-analysis execution. 
Scales such as these are useful tools, capable of organizing surgical queues, as usually occurs in other specialties, such as organ transplants, and must be adapted to the reality of the health services that intend to adopt it. The proposed scale aims to support regional characteristics needs and can be modified and improved over time. Our scale were developed only for research purposes and were not implement in our patients or institution.

Studies with clinical correlation are necessary for its implantation. The adoption of criteria for the organization of the surgical row for scoliosis aims a better serve the patients who would have greater benefits, fewer risks for surgical treatment, with better costeffectiveness. These aspects should be the object of future studies. Scale could be improved during time according future concernings and sugestions. 


\section{References}

1. Scoliosis Research Society (2018) Adolescent Idiopathic Scoliosis, Brazil.

2. Soucacos PN, Zacharis K, Gelalis J, Soultanis K, Kalos N, et al. (1998) Assessment of curve progression in idiopathic scoliosis. Eur Spine J 7: 270-7.

3. Bunnell WP (1986) The Natural History of Idiopathic Scoliosis Before Skeletal Maturity. Spine 11: 773-6.

4. Nery LS, Halpern R, Nery PC, Nehme KP, Tetelbom Stein A (2010) Prevalence of scoliosis among school students in a town in southern Brazil. Sao Paulo Med J 128: 69-73.

5. Folha de (2017) S. Paulo - Queue for scoliosis surgery is critical in SUS services [S. Paulo - Fila por cirurgia de escoliose é crítica em serviços do SUS], Brazil.

6. Júnior L, De PC, Pellegrino L, Caffaro MFS, Meves R, et al. (2011) Adolescent idiopathic scoliosis (eia): clinical and radiographic profile of the waiting list for surgical treatment in a highly complex tertiary hospital of the Brazilian Public Health System [Escoliose idiopática do adolescente (eia): perfil clínico e radiográfico da lista de espera para tratamento cirúrgico em hospital terciário de alta complexidade do Sistema Público de Saúde Brasileiro]. Coluna/Columna 10: 111-5.

7. Peterson LE, Nachemson AL (1995) Prediction of progression of the curve in girls who have adolescent idiopathic scoliosis of moderate severity. Logistic regression analysis based on data from The Brace Study of the Scoliosis Research Society. J Bone Joint Surg Am 77: 823-7.

8. Charles YP, Daures J-P, de Rosa V, Diméglio A (2006) Progression risk of idiopathic juvenile scoliosis during pubertal growth. Spine 31: 1933-42.

9. Weinstein SL, Ponseti IV (1983) Curve progression in idiopathic scoliosis. J Bone Joint Surg Am 65: 447-55.

10. Weinstein SL, Dolan LA, Spratt KF, Peterson KK, Spoonamore MJ, et al. (2003) Health and Function of Patients With Untreated Idiopathic Scoliosis: A 50-Year Natural History Study. JAMA 289: 559-67.

11. Weinstein SL, Zavala DC, Ponseti IV (1981) Idiopathic scoliosis: long-term follow-up and prognosis in untreated patients. J Bone Joint Surg Am 63: 702-12.

12. Lonstein JE, Carlson JM (1984) The prediction of curve progression in untreated idiopathic scoliosis during growth. J Bone Joint Surg Am 66: 1061-71.

13. Wiesner R, Edwards E, Freeman R, Harper A, Kim R, et al. (2003) Model for end-stage liver disease (MELD) and allocation of donor livers. Gastroenterology 124: 91-6.

14. Tan K-J, Moe MM, Vaithinathan R, Wong H-K (2009) Curve progression in idiopathic scoliosis: follow-up study to skeletal maturity. Spine 34: 697-700.

15. Zhang Y, Yang Y, Dang X, Zhao L, Ren J, et al. (2015) Factors relating to curve progression in female patients with adolescent idiopathic scoliosis treated with a brace. Eur Spine J Off Publ Eur Spine Soc Eur Spinal Deform Soc Eur Sect Cerv Spine Res Soc 24: $244-8$. 
16. Lee CF, Fong DYT, Cheung KMC, Cheng JCY, Ng BKW, et al. (2012) A new risk classification rule for curve progression in adolescent idiopathic scoliosis. Spine J Off J North Am Spine Soc 12: 989-95.

17. Coillard C, Circo AB, Rivard CH (2014) A prospective randomized controlled trial of the natural history of idiopathic scoliosis versus treatment with the SpineCor brace. Sosort Award 2011 winner. Eur J Phys Rehabil Med 50: 479-87.

18. Lee CS, Hwang CJ, Kim D-J, Kim JH, Kim Y-T, et al. (2012) Effectiveness of the Charleston night-time bending brace in the treatment of adolescent idiopathic scoliosis. J Pediatr Orthop 32: 368-72.

19. Hung VWY, Qin L, Cheung CSK, Lam TP, Ng BKW, et al. (2005) Osteopenia: a new prognostic factor of curve progression in adolescent idiopathic scoliosis. J Bone Joint Surg Am 87: 2709-16.

20. Mao S, Shi B, Xu L, Wang Z, Hung ALH, et al. (2016) Initial Cobb angle reduction velocity following bracing as a new predictor for curve progression in adolescent idiopathic scoliosis. Eur Spine J 25: 500-5.

21. Upadhyay SS, Nelson IW, Ho EK, Hsu LC, Leong JC (1995) New prognostic factors to predict the final outcome of brace treatment in adolescent idiopathic scoliosis. Spine 20: 537-45.

22. Lam TP, Hung VWY, Yeung HY, Chu WCW, Ng BKW, et al. (2013) Quantitative ultrasound for predicting curve progression in adolescent idiopathic scoliosis: a prospective cohort study of 294 cases followed-up beyond skeletal maturity. Ultrasound Med Biol 39: 381-7.

23. Noshchenko A, Hoffecker L, Lindley EM, Burger EL, Cain CM, et al. (2015) Predictors of spine deformity progression in adolescent idiopathic scoliosis: A systematic review with meta-analysis. World J Orthop 6: 537-58.

24. Ahn H, Kreder H, Mahomed N, Beaton D, Wright JG (2011) Empirically derived maximal acceptable wait time for surgery to treat adolescent idiopathic scoliosis. CMAJ Can Med Assoc J Assoc Medicale Can 183: E565-70.

25. Calman R, Smithers T, Rowan R (2013) Impact of surgical waiting time on paediatric spinal deformity patients. ANZ J Surg 83: 929-32.

26. Payne WK, Ogilvie JW, Resnick MD, Kane RL, Transfeldt EE, et al. (1997) Does Scoliosis Have a Psychological Impact and Does Gender Make a Difference? Spine 22: 1380-4.

27. Freidel K, Petermann F, Reichel D, Steiner A, Warschburger P, et al. (2002) Quality of life in women with idiopathic scoliosis. Spine 27: E87-91.

28. Carrasco MIB, Ruiz MCS, Carrasco MIB, Ruiz MCS (2014) Perceived self-image in adolescent idiopathic scoliosis: an integrative review of the literature. Rev Esc Enferm USP 48: 748-57.

29. Sapountzi-Krepia D, Psychogiou M, Peterson D, Zafiri V, Iordanopoulou E, et al. (2006) The experience of brace treatment in children/adolescents with scoliosis. Scoliosis 22: 1-8.

30. Brox JI, Lange JE, Steen H (2014) Comorbidity influenced health-related quality of life of 390 patients with idiopathic scoliosis at long-term follow-up. Eur J Phys Rehabil Med 50: 73-81. 
31. Roberts DW, Savage JW, Schwartz DG, Carreon LY, Sucato DJ, et al. (2011) Male-female differences in Scoliosis Research Society-30 scores in adolescent idiopathic scoliosis. Spine 36: E53-9.

32. Sanders JO, Khoury JG, Kishan S, Browne RH, Mooney JF, et al. (2008) Predicting Scoliosis Progression from Skeletal Maturity: A Simplified Classification During Adolescence: J Bone Jt Surg-Am 90: 540-53.

33. Taylor MC, Hadorn DC (2002) Developing priority criteria for general surgery: results from the Western Canada Waiting List Project. Can J Surg 45: 351-7.

34. Brasil Government (2017) SUS will have a single line in each state for elective surgeries [SUS terá fila única em cada estado para cirurgias eletivas], Brazil.

35. Lewis S, Barer ML, Sanmartin C, Sheps S, Shortt SE, et al. (2000) Ending waiting-list mismanagement: principles and practice. Can Med Assoc J 162: 1297-300.

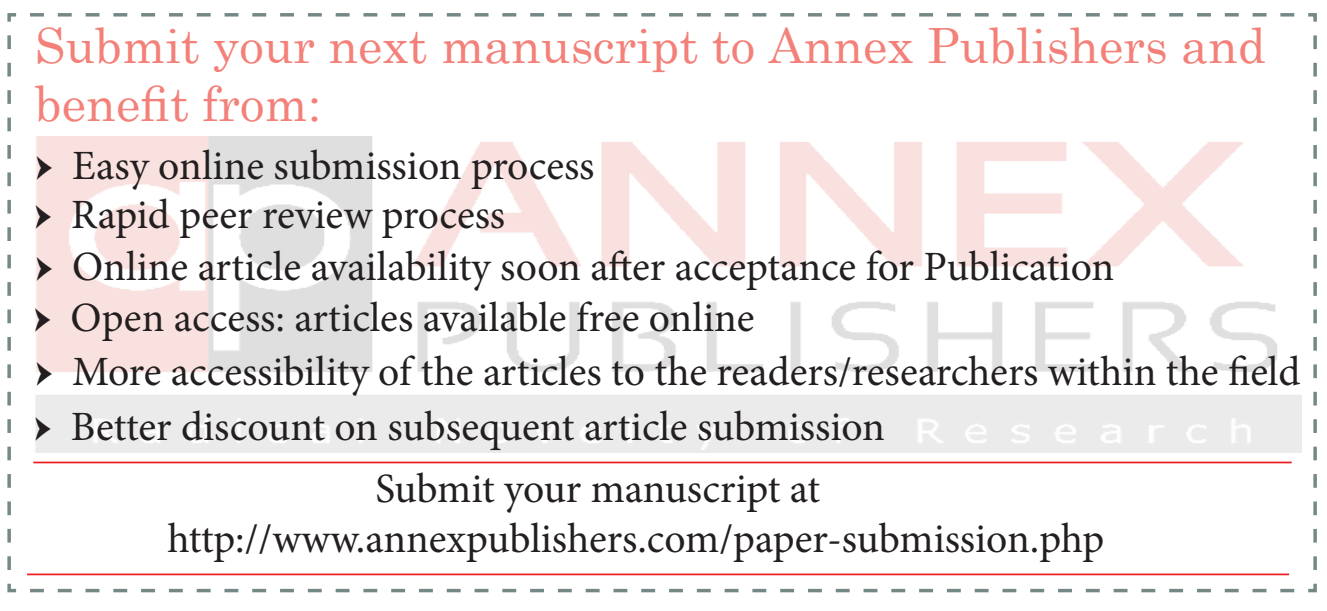

